\title{
Extraction and Evaluation of Anti-helminthic Activity of Hibiscus Cannabis. L
}

\author{
Ravalli $\mathbf{R}^{1^{*}}$, Sushma B ${ }^{2}$, Nageswara Rao KVV ${ }^{3}$, Bhimji Ambedkaru $\mathrm{K}^{4}$ and Amala Reddy $\mathrm{J}^{5}$ \\ ${ }^{1}$ Deparment of Medicinal Chemistry, Andhra University, Vishakapatnam, India \\ ${ }^{2}$ Deparment of Medicinal Chemistry, National Institute of Pharmaceutical Education and Research (NIPER) Hyderabad, India \\ ${ }^{3,4}$ Deparment of Pharmaceutical Sciences, Andhra University, Vishakapatnam, India \\ ${ }^{5}$ Deparment of Pharmaceutical Sciences, Osmania University, Hyderabad, India \\ *Corresponding author: Ravalli R, Deparment of Medicinal Chemistry, Andhra University, Vishakapatnam, India, tel: 91-9491259469; E-Mail: \\ ravalli.remella@gmail.com
}

Received date: January 06, 2015, Accepted date: March 06, 2015, Published date: March 12, 2015

Copyright: $\odot 2015$ Ravalli R, et al. This is an open-access article distributed under the terms of the Creative Commons Attribution License, which permits unrestricted use distribution, and reproduction in any medium, provided the original author and source are credited.

\begin{abstract}
According to the literature review, it was found that various activities was done and reported on Hibiscus cannabis $L$., But anthelminthic activity of the leaves of the plant Hibiscus Cannabis $L$ were not reported. So, my present work is aimed to carry out the Extraction \& Isolation, Phytochemical screening, and estimation of anti-helminthic activity, anti-oxidant activity of hydro alcoholic extract, ethanolic extract, and water extract of Hibiscus Cannabis $L$.
\end{abstract}

\section{Introduction}

A natural product [1] is a substance or chemical compound often produced by a living organism - found in nature that typically features a pharmacologic or biological activity to be used in pharmaceutical drug discovery and drug designing. Even though it is prepared by total synthesis it is also considered as a natural product.

\section{Natural products as medicines: History and the earliest known medicines to man}

For thousands of year's natural product have played awfully a vital role in health care and hindrance of diseases [2]. the traditional civilizations of the Chinese, Indians and North Africans offer written proof for the use of natural sources for treating various diseases.

According to recent survey conducted by the World Health Organization, nearly $80 \%$ of the world's total population depends on ancient medication [3] regarding 121 medicines prescribed in USA today come from natural sources, ninety of that return either directly or indirectly from plant sources. $47 \%$ of the antitumor drugs within the market return from natural products or natural product mimics.

\section{Types of Natural products}

\section{Natural products from microorganisms}

Microorganisms as a supply of potential drug candidates weren't explored till the invention of antibiotic drug, like penicillin in 1929 [4]. Since then, an outsized range of terrestrial and marine microorganisms were screened for drug discovery. Microorganisms have an unlimited range of potentially active substances and have led to the invention of antibacterial drug agents like cephalosporins, and diabetic agents like acarbose, and antitumor agents like paclitaxel [5].

\section{Natural products from marine organisms}

The first active compounds to be isolated from marine species were spongouridine and spongothymidine from the Carribean sponge
Cryptothecacryptain in Nineteen Fifties. These antiviral and anticancer agents are highly potential and the compound is nucleotides [6]. Their led to an in depth analysis to spot novel drug discovery from marine sources. Concerning seventieth of the earth's surface is roofed by the oceans, providing vital multifariousness for exploration for drug sources. Several marine organisms have asedentary fashion, and thereby synthesize several advanced and very potent chemicals as their means that of defense from predators. These chemicals will function as possible remedies for various ailments, particularly cancer [7]. One such example is discodermolide, isolated from the marine sponge, Discodermiadissoluta, that incorporates a similar mode of action similar to that of paclitaxol and possesses a potent anticancer activity. It also shows higher water solubility as compared to paclitaxel [8]. A combination therapy of the two drugs showed potent anticancer activity.

\section{Materials and Methods}

\section{Collection, Identification and Authentication of the Hibiscus cannabis $L$}

The fresh leaves of the plant Hibiscus. Cannabis were collected from the surrounding areas of Injaram, East Godavari district, Andhra Pradesh. The plant was identified \& authenticated by the Dr. M. Raghuram, Professor, Department of Botany\& microbiology in Acharya Nagarjuna University, Guntur.

\section{Extraction}

- The plant was collected and cleaned with water and the leaves were separated from the plant.

- The leaves are shade dried for a period of 3-4 days, then it was powdered \& sieved with sieve no 44

\section{Extraction by maceration}

In this method, the full or coarsely pulverised crude drug is placed in a stoppered flask with the solvent and allowed to stand at room 
temperature for minimum of three days with frequent agitation till the soluble matter has dissolved [9]. The mixture was strained, (the damp solid material) i.e marc is pressed, and also the combined liquids are subjected to filtration or decantation after standing.

\section{Circulatory extraction}

The powdered plant material was weighed and the powder was placed in a conical flask and 50\% hydro alcohol (ethanol: water 1:1) was added to it until the powder was fully soaked and $1 \mathrm{ml}$ of benzene was added to it to avoid microbial contamination and is allowed to stand for $48 \mathrm{hrs}$ [10]. The powdered plant material was weighed and was placed in a conical flask and ethanol was added to it until the powder was fully soaked and allowed to stand for $48 \mathrm{hrs}$ [11].

After $48 \mathrm{hrs}$ the mixture was filtered by using Buchner funnel, the filtrate containing drug and drug extract, the mixture was subjected to distillation process by the distillation process alcohol was separated out and the crude drug extracts using the specific solvents were separated, the hydro alcoholic extract contains water so it needs to be separated in order to concentrate the extract [12]. The water was removed by heating at $100^{\circ} \mathrm{C}$ in the hydro alcoholic extract, the water was evaporated and the drug extract changes into thick viscous substance the crude drug substance was ready to use for the further tests and the hydro alcoholic and ethanolic extract obtained is evaluated for anti-helminthic activity.

\section{Phytochemical evaluation}

Test for flavonoids: Shinoda Test: To the extract, a few magnesium turnings and 1-2 drops of conc. $\mathrm{HCl}$ were added; red colour was observed indicates the absence of flavones [13].

To the extract, $10 \%$ sodium hydroxide or ammonia was added, dark yellow color was observed indicates the absence of flavones.

Test for glycosides: Legal's test: To the extract add $1 \mathrm{ml}$ of pyridine, $1 \mathrm{ml}$ of sodium nitroprusside, pink colour was not observed Indicates the absence of glycosides [14].

Test for alkaloids: Dragendroffs Test: In a test tube containing $1 \mathrm{ml}$ of extract, few drops of dragendroff's reagent was added, orange color was not observed Indicates the absence of alkaloids [15].

Test for Fixed oils: To 5 drops of sample added $1 \mathrm{ml}$ of copper sulphate solution then add $10 \% \mathrm{NaOH}$ solution. A clear solution is obtained which shows glycerine is present in the sample. The cupric hydroxide formed in the reaction does not precipitate out as it is soluble in glycerine [16-19].

To 5 drops of the sample added a pinch of sodium hydrogen sulphate; pungent odour emanates indicating presence of glycerine [20].

\section{Biological Evaluation}

The extracted compound was subjected to investigate the following biological studies

\section{Anti-helminthic activity}

Gastrointestinal parasites create a serious threat to the production of livestock in developing nations. As per WHO, only few drugs are frequently used in the treatment of helminthes in human beings [21]. Helminthes parasite infections are globally a problem with serious social and economic repercussions in developing countries. Some helminthe infections such as filariasis has solely a few therapeutic modalities nowadays.

The continuous and frequent dependency on a small range of compounds has led to drug resistance in several helminthic strains. Additionally, treating with albendazole led to several side effects, where the individuals reported allergy, nervous system symptoms, GIT disturbances and allergic phenomena. Some anthelmintic medication, like praziquantel and albendazole, are contraindicated in lactating and pregnant women. These medications are also contraindicated in patients suffering from hepatitis and in children below 2 years of age.

The anthelmintic assay was performed in vitro using adult earth worm that is P. Megascolex, since it has anatomical and physiological similarities with the intestinal round worm of human beings for the preliminary analysis of anthelmintic activity.

\section{Materials and Methods}

Experimenatal animals Collection: The worms Collection Indian earthworm P. megascolex were collected from the Garden soil of Pydah College of Pharmacy, patavala road, Kakinada, Andhra Pradesh and authenticated from P. Anitha susan, HOD and Reader, Department of Zoology, Andhra Christian College. Indian adult earthworms (Pheretima megascolex) were used to study anthelmintic activity. The earthworms were collected, washed with normal saline to remove all fecal matter. The earthworms of 5-8 cm in length and $0.2-0.3 \mathrm{~cm}$ in width were used for all experimental protocol.

Drugs \& Chemicals: Isolated leaf extracts of Hibiscus Cannabis plant and standard drug Albendazole

Procedure: The synthesized derivative compounds were screened for anthelmintic activity .Earth worms of nearly equal size $(6 \mathrm{~cm} \pm 1)$ were selected randomly for present study. The worms were acclimatized to the laboratory condition before experimentation $[22,23]$. The earthworms were divided into three groups of six earth worms each. Six earthworms of nearly equal size were placed in standard drug solution and test compound's solutions at room temperature. Normal saline used as control. Standard drug and test compounds $10 \mathrm{mg}, 50 \mathrm{mg}$ and $100 \mathrm{mg}$ were dissolved in minimum quantity $(2 \mathrm{ml})$ of dimethyl formamide (DMF) and adjusted the volume up to $15 \mathrm{ml}$ with normal saline solution. The test compounds and standard were evaluated by the time taken for complete paralysis and death of earthworms. The mean lethal time for each test compound was recorded and compared with standard drug. The time taken by worms to become motionless was noted as paralysis time shown in Figure 1,2. To ascertain the death of the motionless worms were frequently applied with external stimuli, which stimulate and induce movement in the worms, if alive. The mean lethal time and paralysis time of the earthworms for different test compounds and standard drug were tabulated in the results section respectively.

\section{Statistical Analysis}

The results were expressed as Mean \pm SEM and statistically analyzed by one way ANNOVA followed by Dunnett's multiple Comparison Test with level of significance set at $\mathrm{P}<0.05$ Figures 1 and Figure 2. 
Citation: Ravalli R, Sushma B, Nageswara Rao KVV, Bhimji Ambedkaru K and Amala Reddy J (2015) Extraction and Evaluation of Antihelminthic Activity of Hibiscus Cannabis. L. Med chem 5: 0003-R. doi:10.4172/2161-0444.1000003-R

Page 3 of 4

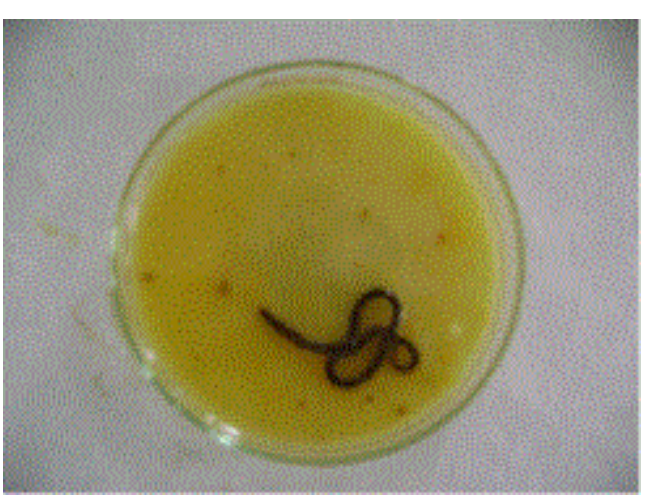

Figure1: Earthworm undergoing Paralysis

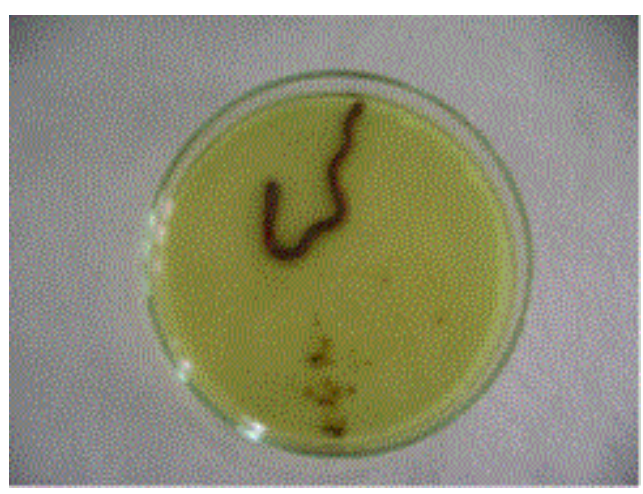

Figure 2: Earthworm undergoing Death

\section{Results}

The Hydro alcohol extract and Ethanolic extract of the plant Hibiscus Cannabis was evaluated for Anti-helminthic activity by Earth Worm model at $10 \mathrm{mg}, 50 \mathrm{mg}$ and $100 \mathrm{mg}$. Standard was taken as Albendazole. Control was taken as Saline and DMF. The results were shown in (Tables 1 and 2) (Figures 3 and 4).

\begin{tabular}{|l|l|l|l|}
\hline \multirow{2}{*}{ Conc (in mg) } & \multicolumn{2}{l}{ Time in Minutes \pm EM } & Ethanolic Extract \\
\cline { 2 - 4 } & Albendazole & $\begin{array}{l}\text { Hydroalcohol } \\
\text { Extract }\end{array}$ & 14.65 \\
\hline 10 & 15.86 & $10.24^{* * *}$ & $9.85^{* *}$ \\
\hline 50 & 10.45 & 8.45 & 5.86 \\
\hline 100 & 6.82 & 4.32 & \\
\hline
\end{tabular}

Table1: Paralysis time for isolated plant extract of Hibiscus Cannabis

\begin{tabular}{|l|l|l|l|}
\hline \multirow{2}{*}{ Conc (in mg) } & \multicolumn{3}{|l|}{ Time in Minutes \pm EM } \\
\cline { 2 - 4 } & Albendazole & $\begin{array}{l}\text { Hydroalcohol } \\
\text { Extract }\end{array}$ & $\begin{array}{l}\text { Ethanolic } \\
\text { Extract }\end{array}$ \\
\hline 10 & 20.65 & $18.65^{\star \star *}$ & 15.25 \\
\hline
\end{tabular}

\begin{tabular}{|l|l|l|l|}
\hline 50 & 15.89 & 14.56 & 10.23 \\
\hline 100 & 9.35 & 8.98 & 9.23 \\
\hline $\begin{array}{l}\text { Where, Std. = Albendazole, Control=Saline + DMF, SEM = standard Error } \\
\text { Mean, }{ }^{* * *}=\text { potent }(p<0.05)\end{array}$ \\
\hline
\end{tabular}

Table 2: Death time for isolated plant extract of Hibiscus Cannabis

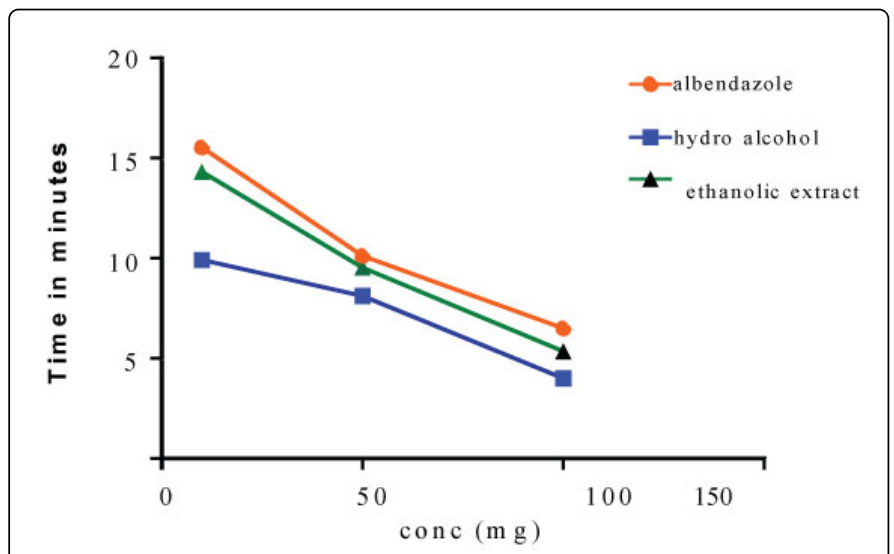

Figure 3: Paralysis time of Albendazole and Hydroalcohol extract

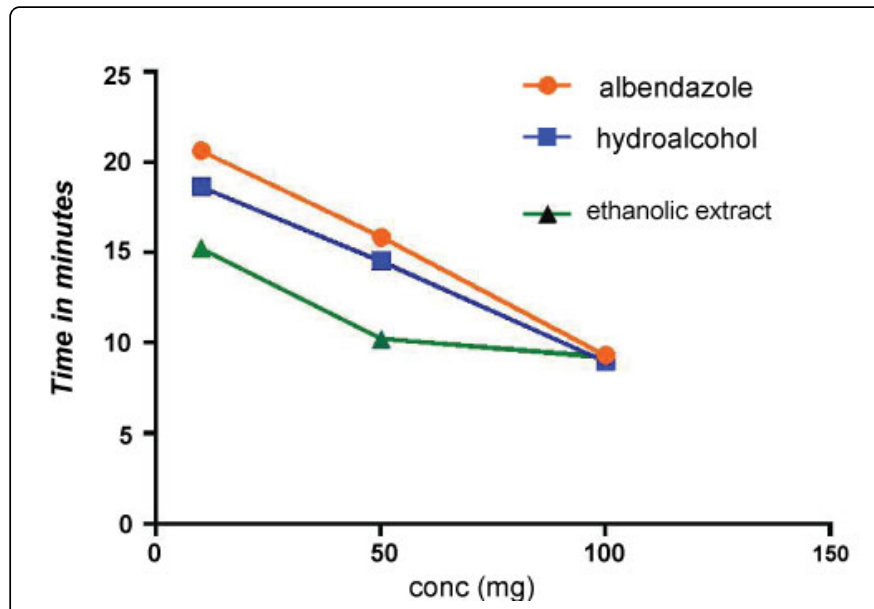

Figure 4: Death time of Albendazole and Hydroalcohol extract

\section{Conclusion}

As shown in the results hydro alcohol extract of the leaves of Hibiscus Cannabis extract showed potent activity when compared to the ethanolic extracts of the plant Hibiscus Cannabis $L$ and the solvent fractions exhibiting considerable activity (dose dependent) when compared with reference standard. The present research work showed the validity and the clinical use of hydro alcohol extract of Hibiscus Cannabis in the control of anti-helminthic activity. However further investigation required for chemical and pharmacological properties.

\section{References}

1. Newman DJ, Cragg GM (2007) Natural products as sources of new drugs over the last 25 years. J Nat Prod 70: 461-477. 
Citation: Ravalli R, Sushma B, Nageswara Rao KVV, Bhimji Ambedkaru K and Amala Reddy J (2015) Extraction and Evaluation of Antihelminthic Activity of Hibiscus Cannabis. L. Med chem 5: 0003-R. doi:10.4172/2161-0444.1000003-R

Page 4 of 4

2. Phillipson JD1 (2001) Phytochemistry and medicinal plants. Phytochemistry 56: 237-243.

3. Kong JM, Goh NK, Chia LS, Chia TF (2003) Recent advances in traditional plant drugs and orchids. Acta Pharmacol Sin 24: 7-21.

4. Bensky D (2004) Chinese Herbal Medicine: Materia Medica, 3rd Ed. Seattle: Eastland Press Incorporated.

5. Arirudran B, Saraswathy A (2011) Evaluation of antioxidant potential of Hibiscus Cannabis L. using in-vitro mode. Journal of Pharmacy Research 4: 4344-4347.

6. Manikandan A, Victor Arokia Doss D (2010) Effect of 50\% Hydroalcoholic Leaf Extracts of Hibiscus Cannabis L. and Dipteracanthus patulus (Jacq) on Non-enzymic Antioxidants and other Biochemical Parameters in Liver, Kidney, Serum of Alloxan Induced Diabetic Swiss Albino Rats. Journal of Biomed Science and Research 2: 190-201.

7. Alam M, Ashraful, Subhan Nusrat (2009) Antinociceptive and antiinflammatory properties of Hibiscus Cannabis L. Pharmaceutical Biology Formerly International Journal of Pharmacognosy 47: 209-214.

8. Chwan-Fwu Lin, Yu-Ling Huang (2006) Bioactive Flavonoids from Hibiscus Cannabis. Journal of Biomed Science and Research 17: 103-109.

9. Melecchi MIS, Martinez MM, Abad FC, Zini PP, Caramão EB, et al. (2002) Chemical composition of Hibiscus tiliaceus L. flowers: A study of extraction methods. Journal of separation science 25: 86-90.

10. Arambewela LSR, Thambugala SR, Ratnasooriya WD (2003) Gastro protective activity of Hibiscus Cannabis $L$ whole plant extract. Journal of Tropical Medicinal Plants 4.

11. Daya L, Chothani MB, Patel (2012) Isolation of Marker Compound of Hibiscus Cannabis, Chromatography. Research International journal 2012: 103-109.

12. Ogbonnaya CI, Roy-Macauley H, Nwalozie MC, \& Annerose DJM (1997) Physical and histochemical properties of kenaf (Hibiscus cannabinus L.) grown under water deficit on a sandy soil. Industrial Crops and Products, 7: 9-18.
13. Czeczot H, Tudek B, Kusztelak J, Szymczyk T, Dobrowolska B, et al. (1990) Isolation and studies of the mutagenic activity in the Ames test of flavonoids naturally occurring in medical herbs. Mutation Research/ Genetic Toxicology 240: 209-216.

14. Khandelwal K (2008) Practical pharmacognosy. Pragati Books Pvt. Ltd.

15. Firdouse S, Alam P (2011) Phytochemical investigation of extract of Amorphophallus campanulatus tubers. International journal of Phytomedicine 3: 32-35.

16. Hajhashemi V, Ghannadi A, Jafarabadi H (2004) Black cumin seed essential oil, as a potent analgesic and antiinflammatory drug. Phytotherapy Research 18: 195-199.

17. Phakeovilay C, Disadee W, Sahakitpichan P, Sitthimonchai S, Kittakoop P, et al. (2013) Phenylethanoid and flavone glycosides from Ruellia tuberosa L. J Nat Med 67: 228-233.

18. Chothani DL, Mishra SH, Patel MB (2011) Phytochemical screening and physicochemical evaluation on various parts of Hibiscus Cannabis L Inventi journals.

19. Arirudran B, Saraswathy A (2011) Pharmacognostic and Preliminary Phytochemical Studies on Ruellia tuberosa L. (Whole plant) journal of Metadata 3: 29-34.

20. Chiobouaphong Phakeovilay (2012)Wannaporn Disadee; Phenylethanoid and flavone glycosides from Hibiscus Cannabis L, Journal of natural medicines 67: 228-233.

21. Bačíková D, Betina V, Nemec P (1965) Antihelminthic activity of antibiotics. Letters to nature 206: 1371-1372.

22. Molodykh ZV, Lisenkova AN, Buzykin BI, Kimaev IU (1977) Antihelminthic activity of some hydrazones. Food and agricultural organization of US 81-83.

23. Anichina K, Vutchev D, Mavrova A (2006) Antihelminthic activity of new piperazine containing benzimidazole. Probl. Inf. Parasit 1: 19. 